\title{
Age and Race Specific Trends and Mortality for Dementia Hospitalization in the US
}

Dean Sherzai ${ }^{1,2}$, Ayesha Sherzai ${ }^{1,2 *}$, Medina Sahak ${ }^{2}$ and Chizobam Ani ${ }^{3}$

${ }^{1}$ Departments of Neurology and Neurosurgery, Cedars Sinai Medical Center, Los Angeles, California, USA

${ }^{2}$ Loma Linda University School of Public Health, Loma Linda, California, USA 3Charles R. Drew University of Medicine and Science, Los Angeles, California, USA

\begin{abstract}
Objective: To explore ethnoracial and gender specific mortality associated with dementia hospitalizations from 1997 to 2008 , using a nationally representative database.

Design: Cross-sectional.

Participants: $354,949,163$ from the Nationwide Inpatient Sample (NIS) database using appropriate ICD-9 and procedure codes.

Measurements: Descriptive, univariate and multivariable analysis (Linear, Cox) adjusting for comorbidity, hospital factors and socio-demographics were used.

Results: Mortality was higher for dementia hospitalizations for all age groups (35-64 years and $\geq 65$ years) vs. non-dementia hospitalizations $(2.7 \%$ vs. $1.5 \%$ and $5.5 \%$ vs. $4.5 \%)$. For individuals aged $35-64$ years, dementia hospitalizations were more common among males vs. females $(53.8 \%$ vs. $46.2 \%)$. Crude in-hospital mortality was higher among Whites and males for all age groups and overall mortality declined from 1999 to 2008 . Adjusted relative risk of mortality was higher among men as compared to women of all age groups (RR 2.87, 95\% $\mathrm{Cl} 2.82-2.92$ ) and also higher among Hispanics and African Americans as compared to Whites (African Americans: RR 2.35, 95\% Cl 2.21-2.51; Hispanics: RR 2.15, 95\% Cl 2.06-2.23).
\end{abstract}

Conclusion: African Americans, Hispanics and men bear a disproportionate burden from dementia in the hospital setting. Interventions to improve care outcomes in these populations are important.

Keywords: Dementia; Aging; Gender; Race; In-hospital mortality

\section{Introduction}

Dementia is a grave and costly public health issue affecting 5.3 million elderly in the U.S., with the number projected to triple by 2050 [1]. It is frequently complicated by multiple co-morbidities, thereby increasing the risk for hospitalizations and adverse outcomes [2,3]. There is mixed evidence regarding the role of gender on dementia incidence, morbidity and mortality. While some studies report higher risk in women compared to men [4,5], others report greater [6] or no difference in incidence among men [7-12]. Though there is evidence of greater mortality rate among men with dementia [13-18]. Others have higher mortality among women [19-20] especially the oldest old women. However, there seems to be insufficient data to conclude that mortality difference exists based on gender when adjusted for comorbidity and age.

While incident dementia is more common among whites, some evidence suggests that differences in incidence, morbidity and mortality may exist based on race and ethnicity. Some studies suggest that the minority populations may be disproportionately affected. For example, Alzheimer's Association has estimated the prevalence of Alzheimer dementia (ALZ-D) and other dementias in African Americans 65 years and above to be twice that seen among whites of the same age group, while the prevalence among Hispanics is one and half times greater than in Whites [21]. Other studies have corroborated these findings [22-25]. Few studies in contrast report no difference [26,27]. To the best of our knowledge, no study that we know of has looked at hospitalization by race and ethnicity, especially exploring the trends over the past decade.

Finally there is a dearth of data regarding dementia-associated comorbidities among hospitalized patients, and any change in trend over time. In this study, we propose to examine ethnicity, race, gender, and comorbidity specific outcomes associated with dementia hospitalization in the US, including any trends or changes in these outcomes over the past decade (1999-2008).

\section{Methods}

Data was obtained from the Nationwide Inpatient Sample (NIS), developed as part of the Healthcare Cost and Utilization Project, a Federal-State-Industry partnership sponsored by the Agency for Healthcare Research and Quality (AHRQ). NIS is designed to approximate a stratified $20 \%$ sample of all non-federal, short-term, general, and specialty hospitals serving adults in the United States [28]. The sampling strategy selects hospitals nationwide from State Inpatient Database according to defined strata based on ownership, bed size, teaching status, urban or rural location, and region. All discharges from sampled hospitals for the calendar year are then selected for inclusion into NIS. To allow extrapolation for national estimates, both hospital and discharge weights are provided. Detailed information on the design of the NIS is available at http://www.hcup-us.ahrq.gov.

*Corresponding author: Ayesha Sherzai, Cedars Sinai Medical Center, 127 San Vicente Blvd, A 6228, Los Angeles, CA 90048, USA, Tel: 310-423-6472; Fax: 310423-0148; E-mail: ayesha.sherzai@cshs.org

Received February 01, 2016; Accepted February 24, 2016 ; Published February 29, 2016

Citation: Sherzai D, Sherzai A, Sahak M, Ani C (2016) Age and Race Specific Trends and Mortality for Dementia Hospitalization in the US. J Neurol Neurophysiol 7: 358. doi:10.4172/2155-9562.1000358

Copyright: ( 2016 Sherzai D, et al. This is an open-access article distributed under the terms of the Creative Commons Attribution License, which permits unrestricted use, distribution, and reproduction in any medium, provided the original author and source are credited. 
From 1999-2008, NIS captured discharge-level information on primary and secondary diagnoses and procedures, discharge vital status, and demographics on discharges per year. Data elements that could directly or indirectly identify individuals were excluded; we thus considered all discharge encounters to be independent. The unit of analysis was the discharge/encounter rather than the individual. A unique hospital identifier allows for linkage of discharge data to an NIS data set with hospital characteristics. To analyze Dementia hospitalizations, we identified all discharge codes, for which an ICD9CM code of 290.X (X including 290.0, 290.10, 290.11, 290.12, 290.13, 290.20, 290.21, 290.3, 290.40, 290.41, $290.42,290.43,294.0), 294 . X$ (X including 294.1), 331.0, 331.X (X including 331.11, 331.19, 331.82, 331.89), 332.0, and 333.0 were all designated as 'Dementia' as the primary diagnosis. This approach has been employed by other studies and was taken to specifically focus on encounters with Dementia as the primary diagnosis and not those encounters for which dementia was a secondary diagnosis. The total numbers of Dementia hospitalizations were obtained by summing across all identified ICD9-CM codes. For encounters which had more than one reported code, only the first reported code was used. Similar coding algorithms were utilized for in-hospital procedures and other medical co-morbidity that were analyzed. We were careful to account for code changes if they occurred per NIS guidelines. The burden of co-morbidities was assessed using the Charlson-Deyo Index (CDI) methodology [29].

\section{Statistical Analysis}

Descriptive analysis and normalization of non-normal variables including the primary outcome (mortality) and predictor/independent variables were conducted. We also examined trends in the distribution of these variables from 1999 to 2008. Next we examined crude inhospital mortality by gender, age-group and race/ethnicity. We also explored the relationship between age-groups, gender, race/ethnicity and in-hospital mortality using univariate and multivariable Cox proportional Hazards analysis. Finally, we examined the trends in in- hospital mortality from 1999 to 2008 . Adjustments in the multivariable models were made for socio-demographic factors, clinical comorbidity and hospital characteristics. Appropriate NIS sampling and design parameters were applied during this analysis. All data analyses were conducted using SPSS (version 20.0 with the complex samples module) and SAS version 9.2 (SAS Institute, Inc., Cary, NC). This study was deemed exempt by the Cedars-Sinai and Loma Linda University Institutional Review Board.

\section{Results}

Baseline characteristics of the population are outlined in Table 1. We identified 221,071 young dementia hospitalization and 7,219,708 old dementia hospitalization. Dementia was greater among Whites when compared to other ethnicities (35-64: 65.1\%, $\geq 65$ : 82.4\%). Among individuals aged between 35-64 years, there were more women with non-dementia hospitalization (54.3\%), but more men were hospitalized with dementia (Men 53.8\%, Women 46.2\%). Among those between 35-64 years of age, inflation adjusted hospital charges was greater for dementia cases in comparison to non-dementia cases (Dementia $\$ 25,050$, non-dementia $\$ 23,689$ ), yet among those $\geq 65$ years of age, inflation-adjusted charges were significantly lower among the dementia patients (Dementia $\$ 20,229$, non-dementia $\$ 26,048$ ). As demonstrated in Table 2, the Comorbidity Index score was higher among nondementia hospitalization compared to dementia hospitalization among those $\geq 65$ years of age (1.93 vs. 1.45). Significant differences were observed in the distribution of medical comorbidities. Of particular importance was the high occurrence of chronic obstructive pulmonary disease (COPD), hypertension (HTN), heart failure, diabetes mellitus (DM) with complications, chronic renal disease, and HIV/AIDS among the younger group (age 35-64 years). For example, COPD occurred more among individuals with dementia compared to non-dementia ( $14.7 \%$ vs. $9.7 \%$ ), HTN was also higher ( $51.7 \%$ vs. $37.3 \%)$, and heart failure almost three times higher (10.09\% vs. 3.7\%).

The same variations were not observed in similar magnitude among

\begin{tabular}{|c|c|c|c|c|}
\hline \multirow[b]{2}{*}{ Variables } & \multicolumn{2}{|c|}{ Age 35-64years } & \multicolumn{2}{|c|}{ Age $\geq 65$ years } \\
\hline & $\begin{array}{l}\text { No Dementia } \\
\% / \text { Mean SE }\end{array}$ & $\begin{array}{l}\text { Dementia } \\
\text { \%/Mean SE }\end{array}$ & $\begin{array}{l}\text { No Dementia } \\
\% / \text { Mean SE }\end{array}$ & $\begin{array}{l}\text { Dementia } \\
\% / \text { Mean SE }\end{array}$ \\
\hline$n$ & $232,961,023$ & 221,071 & $114,547,361$ & $7,219,708$ \\
\hline Age & $50.03[0.32]$ & $58.59[0.04]$ & $77.4[0.03]$ & $83[0.03]$ \\
\hline \multicolumn{5}{|l|}{ Gender } \\
\hline Male & 45.6 & 53.8 & 42.9 & 35.7 \\
\hline Female & 54.3 & 46.2 & 57.1 & 64.3 \\
\hline \multicolumn{5}{|l|}{ Primary payer } \\
\hline Medicare & 16.9 & 49.3 & 89.3 & 92.8 \\
\hline Medicaid & 15.8 & 23.3 & 1.5 & 1.4 \\
\hline Private $^{*}$ & 53.8 & 21.3 & 7.8 & 4.7 \\
\hline Other & 13.5 & 6.1 & 1.4 & 1.1 \\
\hline \multicolumn{5}{|l|}{ Race/Ethinicity } \\
\hline White & 71.4 & 65.1 & 84.4 & 82.4 \\
\hline African American & 17.8 & 24.7 & 9.1 & 11.2 \\
\hline Hispanic & 10.8 & 10.2 & 6.6 & 6.4 \\
\hline $\begin{array}{l}\text { Total in-Hospital } \\
\text { Charge }\end{array}$ & $\begin{array}{c}\$ 23,689.94 \\
{[338]}\end{array}$ & $\begin{array}{c}\$ 25,050.28 \\
{[524]}\end{array}$ & $\begin{array}{c}\$ 26,048.05 \\
{[343]}\end{array}$ & $\begin{array}{c}\$ 20,229.44 \\
{[315]}\end{array}$ \\
\hline $\begin{array}{l}\text { Length of Hospital Stay } \\
\text { (mean days) }\end{array}$ & $4.72[0.03]$ & $8.50[0.11]$ & $5.68[0.03]$ & $6.50[0.05]$ \\
\hline
\end{tabular}

*=including $\mathrm{HMO}$

All $p$-values are statistically significant using $p<0.05$ as the level of statistical significance

Table 1: Baseline characteristics of NIS subjects Aged 35-64 and $\geq 65$ years old with and without ICD-9 CM diagnosis of Dementia. 
Citation: Sherzai D, Sherzai A, Sahak M, Ani C (2016) Age and Race Specific Trends and Mortality for Dementia Hospitalization in the US. J Neurol Neurophysiol 7: 358. doi:10.4172/2155-9562.1000358

Page 3 of 6

\begin{tabular}{|c|c|c|c|c|c|c|}
\hline \multirow[b]{2}{*}{ Variables } & \multicolumn{2}{|c|}{ Age 35-64years } & \multirow[b]{2}{*}{$\begin{array}{l}P \text { value (trend } \\
\text { change) }\end{array}$} & \multicolumn{2}{|c|}{ Age $\geq 65$ years } & \multirow[b]{2}{*}{$\begin{array}{c}\text { P value (trend } \\
\text { change) }\end{array}$} \\
\hline & $\begin{array}{l}\text { No Dementia } \\
\% / \text { Mean SE }\end{array}$ & $\begin{array}{c}\text { Dementia } \\
\text { \%/Mean SE }\end{array}$ & & $\begin{array}{l}\text { No Dementia } \\
\% / \text { Mean SE }\end{array}$ & $\begin{array}{c}\text { Dementia } \\
\text { \%/Mean SE }\end{array}$ & \\
\hline$n$ & $232,961,023$ & 221,071 & & $114,547,361$ & $7,219,708$ & \\
\hline Chronic Medical Comorbidity & $1.43[0.01]$ & $1.53[0.02]$ & & $1.93[0.01]$ & $1.45[0.01]$ & \\
\hline COPD & 9.7 & 14.7 & & 21.7 & 16.4 & \\
\hline Stroke & 7.4 & 10.9 & & 10.4 & 18.1 & \\
\hline Heart Failure & 3.7 & 10.9 & & 24.0 & 21.1 & \\
\hline DM with no complications & 14.1 & 20.6 & & 20.0 & 17.1 & \\
\hline DM with complications & 6.7 & 11.2 & & 6.6 & 5.3 & \\
\hline Hypertension & 37.3 & 51.7 & & 58.5 & 54.7 & \\
\hline Paraplegia & 1.5 & 2.4 & & 1.4 & 1.4 & \\
\hline Chronic Renal Disease & 4.6 & 8.6 & & 6.4 & 4.3 & \\
\hline Valvular Heart Disease & 3.6 & 3.4 & 0.075 & 10.2 & 6.9 & \\
\hline HIVIAIDS & 1.6 & 0.7 & & 0.1 & 0.0 & \\
\hline UTI & 5.0 & 16.9 & & 12.1 & 24.8 & \\
\hline Depression & 10.4 & 15.8 & 0.01 & 6.9 & 11.4 & \\
\hline Anxiety & 4.7 & 4.0 & & 3.1 & 2.8 & \\
\hline \multicolumn{7}{|l|}{ Hospital Type } \\
\hline Rural & 12.4 & 15.2 & & 16.8 & 19.2 & \\
\hline Urban non-teaching & 40.9 & 43.1 & & 45.0 & 47.2 & \\
\hline Urban teaching & 46.7 & 41.7 & & 38.2 & 33.5 & \\
\hline \multicolumn{7}{|l|}{ Discharge Disposition } \\
\hline Routine & 80.0 & 35.9 & & 53.7 & 23.9 & \\
\hline Short-term hospital & 2.6 & 2.9 & & 3.1 & 2.1 & \\
\hline Another type of facility/HHC & 14.2 & 57.9 & & 38.3 & 68.4 & \\
\hline Against medical advice & 1.6 & 0.6 & & 0.4 & 0.2 & \\
\hline Died & 1.5 & 2.7 & & 4.5 & 5.5 & \\
\hline
\end{tabular}

SE=standard error, COPD: Chronic Obstructive Pulmonary Disease, DM: Diabetes mellitus, UTI: Urinary Tract Infection, HHC: Home Health Care, All p-values are statistically significant using $p<0.05$ as the level of statistical significance

Table 2: Distribution of medical comorbidities by age-group among subjects with and without Dementia.

\begin{tabular}{|c|c|c|c|c|c|c|}
\hline \multirow[b]{2}{*}{ Age } & \multirow[b]{2}{*}{ Year } & \multicolumn{5}{|c|}{$\%$ Mortality } \\
\hline & & Male & Female & White & African American & Hispanic \\
\hline \multirow{6}{*}{ 35- 64 yrs } & $1999-2000$ & 4.0 & 3.4 & 4.1 & 3.7 & 3.8 \\
\hline & 2001-2002 & 3.3 & 3.5 & 3.6 & 3.7 & 2.9 \\
\hline & 2003-2004 & 2.9 & 2.2 & 2.5 & 2.8 & 4.0 \\
\hline & $2005-2006$ & 2.6 & 2.6 & 3.2 & 2.2 & 2.3 \\
\hline & $2007-2008$ & 2.3 & 1.8 & 2.5 & 1.5 & 1.5 \\
\hline & TOTAL & 2.9 & 2.5 & 3.1 & 2 & 2.8 \\
\hline \multirow{6}{*}{$65-74$ yrs } & $1999-2000$ & 5.5 & 3.9 & 4.8 & 4.9 & 3.4 \\
\hline & 2001-2002 & 4.9 & 3.4 & 4.1 & 4.2 & 4.4 \\
\hline & $2003-2004$ & 3.7 & 3.1 & 3.7 & 3.4 & 3.9 \\
\hline & $2005-2006$ & 3.7 & 2.7 & 3.6 & 2.6 & 2.6 \\
\hline & $2007-2008$ & 3.1 & 2.6 & 2.9 & 3.2 & 2.7 \\
\hline & TOTAL & 4.0 & 3.1 & 3.8 & 3.6 & 3.3 \\
\hline \multirow{6}{*}{$\geq 75$ yrs } & $1999-2000$ & 8.0 & 6.2 & 6.9 & 6.7 & 7.2 \\
\hline & 2001-2002 & 7.5 & 5.8 & 6.5 & 6.4 & 6.5 \\
\hline & 2003-2004 & 7.0 & 5.3 & 6.1 & 5.3 & 6.2 \\
\hline & $2005-2006$ & 6.2 & 4.9 & 5.7 & 4.4 & 5.3 \\
\hline & $2007-2008$ & 5.7 & 4.5 & 5.2 & 4.4 & 5.1 \\
\hline & TOTAL & 6.8 & 5.3 & 6.1 & 5.3 & 5.9 \\
\hline
\end{tabular}

Table 3: Crude in-hospital Dementia mortality by age-group, gender and race/ethnicity.

the older age group (age $\geq 65$ years). Mortality was higher for dementia hospitalizations for all age groups (35-64 years and $\geq 65$ years) vs. nondementia hospitalizations ( $2.7 \%$ vs. $1.5 \%$ and $5.5 \%$ vs. $4.5 \%)$.

Crude In-Hospital Mortality by Age-group, gender and Race/ Ethnicity (Table 3).

Crude in-hospital mortality was observed among three age groups including: $35-64$ years, 65-74 years, and $\geq 75$ years of age (Table 3). Crude in-hospital mortality was higher among among males vs. females for all age groups $(2.9 \%$ vs. $2.5 \%, 4.0 \%$ vs. $3.1 \%$ and $6.8 \%$ vs. $5.3 \%$, respectively). Mortality appeared to decline for all age groups among males and females from 1999 to 2008. Mortality was also higher among Whites when compared with African Americans and Hispanics of all ages. Not surprisingly mortality was highest among the older 
population (75 years or older). Mortality appeared to decline for all age groups among Whites and African Americans from 1999 to 2008. A consistent decline for Hispanics only appeared in the oldest age category ( $\geq 75$ years of age).

Hazard Ratio of Mortality Associated with Dementia Hospitalization by Age-group (Table 4 ).

Unadjusted Cox proportional hazards analysis demonstrated overall higher in-hospital mortality for patients $\geq 75$ years of age when compared with 35-64 year olds and 65-74 year olds (HR 4.65 CI: 4.564.73, HR 1.114 CI: 0.98-1.27, HR 1.24 CI: 1.17-1.31, respectively). Multivariable analysis controlling for the influence of demographic characteristics, medical co-morbidity and hospital characteristics demonstrated similar mortality among the three different age groups. Trends in mortality did not demonstrate any significant change from 1999-2008.

Hazard Ratio of Mortality Associated with Dementia Hospitalization for Whites vs. African Americans and Hispanics (Tables 5).

Multivariable Cox regression analysis demonstrated lower overall mortality for African Americans and Hispanics when compared to Whites hospitalized for dementia.

\section{Discussion}

We believe our study adds to our knowledge of in-hospital mortality associated with dementia, especially as it relates to gender, age and ethnoracial correlates. One important discovery was that higher proportion of African American and Hispanic patients suffering from dementia were hospitalized. Several studies have explored the differences in prevalence and incidence of dementia between the different ethnic groups and to date, most studies have demonstrated greater prevalence of dementia amongst African Americans and Hispanics as compared to whites [23-25,30]. Though our understanding of the biologic and pathophysiologic basis for this disparity in dementia prevalence is still lacking, some reports suggest that environmental factors may play an important role. Literature indicates that African Americans and Hispanics have a higher risk for vascular dementia $[12,31]$ and other cardiovascular diseases, which could account for some of the disparities in the dementia prevalence and mortality. Additionally, there is evidence that minority populations (African Americans, Hispanics) with a diagnosis of dementia often receive delayed or inadequate healthcare services, [32] and specifically, they are less likely than non-Hispanic Whites to be prescribed medication for dementia and related complications [33-35]. This may lead to more admission of more advanced and compromised cases to the hospital, as well as greater mortality in the hospital setting. Given the profound expansion of dementia among the minority population, this difference in hospital mortality necessitates investigation into causal paradigms and potential mitigating interventions.

A notable finding is the increased hospital mortality among men with dementia as compared to women with dementia. Potential explanatory hypotheses regarding this observation may be related to several factors, namely a) neurodegenerative diseases, such as frontotemporal dementia, neurosyphilis and Cruetfeldt Jakob disease, b) infectious diseases including syphilis and AIDS, c) vascular dementia, d) and post-traumatic dementia, among many other causes all being more common in men, and on the average, having an earlier age of onset. Further studies are required to explore the unique presentation, care process, and pathophysiological differences between the genders and age groups.

In our analysis, the younger dementia patients had higher comorbidity index as opposed to the older group with dementia. One reason for our findings could be related to the types of dementias and the comorbidities associated with them. As an example, patients with vascular dementia had the highest comorbidity scores, related to conditions associated with cardiovascular risk: hypertension, hyperlipidemia, stroke, peripheral vascular disease and others [36-39].

\begin{tabular}{|l|c|c|c|}
\hline Age Group & Unadjusted HR (95\% Cl) & $\mathbf{R}^{\mathbf{2}}$ for Trend & $\mathbf{R}^{\mathbf{2}}$ for Trend \\
\hline $35-64$ yrs & $1.11(0.98-1.27)$ & 0.09 & 0.05 \\
\hline $65-74$ yrs & $1.24(0.98-1.27)$ & 0.22 & $1.08(0.93-1.25)$ \\
\hline$\geq 75$ yrs & $4.65(4.56-4.73)$ & 0.48 & $1.16-1.32)$ \\
\hline Total & $1.18(1.16-1.20)$ & 0.22 & $1.20(1.18-1.23)$ \\
\hline
\end{tabular}

*Model adjusted for demographic characteristics, medical co-morbidity and hospital characteristics.

Table 4: Unadjusted and adjusted cox proportional hazard ratios of Dementia hospitalization by age group from 1999-2008.

\begin{tabular}{|c|c|c|c|c|c|c|}
\hline \multirow{4}{*}{ Age Group } & \multicolumn{6}{|c|}{ Unadjusted Cox Proportional Hazards Analysis } \\
\hline & \multicolumn{3}{|c|}{ African American } & \multirow{2}{*}{\multicolumn{3}{|c|}{$\begin{array}{c}\text { Hispanic } \\
1999-2008\end{array}$}} \\
\hline & \multirow[b]{2}{*}{$\mathrm{HR}$} & \multicolumn{2}{|c|}{ 1999-2008 } & & & \\
\hline & & $95 \% \mathrm{Cl}$ & $\begin{array}{c}R^{2} \text { for Trend } \\
1999-2008\end{array}$ & HR & $95 \% \mathrm{Cl}$ & $\begin{array}{c}R^{2} \text { for Trend } \\
1999-2008\end{array}$ \\
\hline $35-64$ yrs & 0.76 & $(0.63-0.92)$ & 0.14 & 0.85 & $(0.65-1.13)$ & 0.04 \\
\hline $65-74$ yrs & 0.86 & $(0.78-0.93)$ & 0.15 & 0.83 & $(0.73-0.95)$ & 0.19 \\
\hline$\geq 75$ yrs & 0.77 & $(0.74-0.81)$ & 0.004 & 0.91 & $(0.85-0.98)$ & 0.05 \\
\hline Total & 0.73 & $(0.70-0.77)$ & 0.01 & 0.87 & $(0.81-0.93)$ & 0.09 \\
\hline \multicolumn{7}{|c|}{ Adjusted Cox Proportional Hazards Analysis ${ }^{a}$} \\
\hline $35-64$ yrs & 0.78 & $(0.65-0.94)$ & 0.002 & 0.92 & $(0.69-1.22)$ & 0.003 \\
\hline $65-74$ yrs & 0.87 & $(0.79-0.98)$ & 0.13 & 0.86 & $(0.75-0.98)$ & 0.25 \\
\hline$\geq 75$ yrs & 0.79 & $(0.75-0.82)$ & 0.01 & 0.92 & $(0.86-0.98)$ & 0.09 \\
\hline Total & 0.77 & $(0.73-0.80)$ & 0.01 & 0.89 & $(0.83-0.95)$ & 0.14 \\
\hline
\end{tabular}

a. Model adjusted for demographic characteristics, medical co-morbidity and hospital characteristics.

*Whites $=$ reference

Table 5: Unadjusted and adjusted cox proportional hazard ratios for in-hospital Dementia mortality by nis year and age group: african americans, hispanics vs. whites*. 
The same increased comorbidity-disease relationship is seen in posttraumatic dementia and HIV dementia. Of interest, heart failure, HTN, DM without complications and HIV were also seen in significantly higher rates in the young dementia group, but not in the older group.

Another cause ascribed to these disparities has been underrecording of comorbidities in older subjects afflicted with cognitive impairment [40-42]. Some of this may be under recording of co morbidities amongst those with do not resuscitate (DNR), do not intubate (DNI) status, but if the under recording goes beyond the DNR and DNI status then it should be explored for a systematic pattern of under treatment in this population group.

In both age groups, COPD had the strongest association with dementia. De Carolis et al. have previously postulated that chronic hypoxia facilitates objectively measured cognitive decline [43]. Our findings are probably the first demonstration of such strong correlation between COPD and dementia in a large population, and may highlight new causal paradigms. In agreement with previous studies, UTI was significantly more common in the dementia group. It is a well-known fact that UTI is one of the most frequent causes for hospitalizations of dementia patients, and is associated with high mortality and morbidity [44].

When looking at in-hospital costs, we observed what ostensibly appeared to be paradoxical results. When comparing the younger and the older dementia groups, despite longer hospital stay in the older dementia group, in-hospital costs were greater in the younger dementia population. As discussed earlier, this could be due to higher level of comorbidities seen in the younger dementia patients. But there could be another reason for this cost disparity; it could attribute it to the tacit beliefs, within the healthcare community, regarding necessity of high level of care in the elderly dementia patients. This is especially interesting in lieu of the fact that length of stay was longer in this group. There is evidence that dementia in the older population, especially in its advanced stages, is viewed as a terminal diagnosis by the families, who often opt for palliative care instead of perceived heroic measures [45]. One reason proposed for prolonged hospital stay in the older dementia patients is that, due to their needs for greater level of care, they often cannot be discharged home, and therefore, finding appropriate placement may lead to delays in discharge. Securing appropriate placement may create delays in placement. Given the aging of our society and significantly greater number of dementia patients coming to the hospital, the questions of quality of care, cost, and appropriate placement will need greater attention.

\section{Limitations}

This study is subject to important limitations including the use of administrative data that extrapolates Dementia occurrence using ICD-9 coding. Coding errors may be over- or under reported. Medical comorbidity patterns described in this study are also dependent on appropriate coding, and coding errors may also affect observed outcomes. Though rare, discharge disposition and mortality estimates may not account for transfer between hospitals or facilities for the selected population. Despite these limitations, we believe this study presents an important insight into the ethnoracial, gender and comorbidity correlates associated with dementia hospitalizations.

\section{Conclusion}

We were able to demonstrate that Whites and men face a disproportionate risk of mortality in the hospital setting. It is also evident that younger dementia patients have more comorbidities compared to older dementia patients. Yet it is not clear if this is related to differences in level of care or type of disease. Paradoxically, though hospital stay for the older dementia group as compared to the younger group was longer, cost of hospitalization was lower. It is important to elucidate whether this is due to causal differences or level of care. As the population is getting older at an unprecedented rate, and we will face an epidemic of dementia and dementia related hospitalization, we will need to better understand the comorbid risks, and the level and limitations of care in the hospital setting.

\section{References}

1. Sloane PD, Zimmerman S, Suchindran C, Reed P, Wang L, et al. (2002) The public health impact of Alzheimer's disease, 2000-2050: potential implication of treatment advances. Annu Rev Public Health 23: 213-231.

2. Phelan EA, Borson S, Grothaus L, Balch S, Larson EB (2012) Association of incident dementia with hospitalizations. JAMA 307: 165-172.

3. Marengoni A, Corrao S, Nobili A, Tettamanti M, Pasina L, et al. (2011) Inhospital death according to dementia diagnosis in acutely ill elderly patients: the REPOSI study. Int J Geriatr Psychiatry 26: 930-936.

4. Husaini BA, Sherkat DE, Levine R, Bragg R, Holzer C, et al. (2002) Race, gender, and health care service utilization and costs among Medicare elderly with psychiatric diagnoses. J Aging Health 14: 79-95.

5. Guijarro R, San Román CM, Gomez-Huelgas R, Villalobos A, Martin M, et al (2010) Impact of dementia on hospitalization. Neuroepidemiology 35: 101-108.

6. Ganguli M, Dodge HH, Chen P, Belle S, DeKosky ST (2000) Ten-year incidence of dementia in a rural elderly US community population: the MoVIES Project. Neurology 54: 1109-1116

7. Ruitenberg A, Ott A, van Swieten JC, Hofman A, Breteler MM (2001) Incidence of dementia: does gender make a difference? Neurobiol Aging 22: 575-580.

8. Edland SD, Rocca WA, Petersen RC, Cha RH, Kokmen E (2002) Dementia and Alzheimer disease incidence rates do not vary by sex in Rochester, Minn. Arch Neurol 59: 1589-1593.

9. Nitrini R, Caramelli P, Herrera E, Bahia VS, Caixeta LF, et al. (2004) Incidence of dementia in a community-dwelling Brazilian population. Alzheimer Dis Assoc Disord 18: 241-246.

10. Kukull WA, Higdon R, Bowen JD, McCormick WC, Teri L, et al. (2002) Dementia and Alzheimer disease incidence: a prospective cohort study. Arch Neurol 59: 1737-1746.

11. Ravaglia G, Forti P, Maioli F, Martelli M, Servadei L, et al. (2005) Incidence and etiology of dementia in a large elderly Italian population. Neurology 64 : 1525-1530.

12. Fitzpatrick AL, Kuller LH, Ives DG, Lopez OL, Jagust W, et al. (2004) Incidence and prevalence of dementia in the Cardiovascular Health Study. J Am Geriatr Soc 52: 195-204.

13. Lanska DJ (1998) Dementia mortality in the United States. Results of the 1986 National Mortality Followback Survey. Neurology 50: 362-367.

14. Chandra V, Bharucha NE, Schoenberg BS (1986) Patterns of mortality from types of dementia in the United States, 1971 and 1973-1978. Neurology 36: 204-208.

15. Mölsä PK, Marttila RJ, Rinne UK (1982) Epidemiology of dementia in a Finnish population. Acta Neurol Scand 65: 541-552.

16. Lapane KL, Gambassi G, Landi F, Sgadari A, Mor V, et al. (2001) Gender differences in predictors of mortality in nursing home residents with $A D$. Neurology 56: 650-654.

17. Gambassi G, Lapane KL, Landi F, Sgadari A, Mor V, et al. (1999) Gender differences in the relation between comorbidity and mortality of patients with Alzheimer's disease. Systematic Assessment of Geriatric drug use via Epidemiology (SAGE) Study Group. Neurology 53: 508-516.

18. Helmer C, Joly P, Letenneur L, Commenges D, Dartigues JF (2001) Mortality with dementia: results from a French prospective community-based cohort. Am J Epidemiol 154: 642-648.

19. Foley DJ, Brock DB, Lanska DJ (2003) Trends in dementia mortality from two National Mortality Followback Surveys. Neurology 60: 709-711. 
Citation: Sherzai D, Sherzai A, Sahak M, Ani C (2016) Age and Race Specific Trends and Mortality for Dementia Hospitalization in the US. J Neurol Neurophysiol 7: 358. doi:10.4172/2155-9562.1000358

20. Agüero-Torres H, Fratiglioni L, Guo Z, Viitanen M, Winblad B (1999) Mortality from dementia in advanced age: a 5-year follow-up study of incident dementia cases. J Clin Epidemiol 52: 737-743.

21. Alzheimer's Association (2010) 2010 Alzheimer's disease facts and figures. Alzheimers Dement 6: 158-194.

22. Husaini BA, Sherkat DE, Moonis M, Levine R, Holzer C, et al. (2003) Racial differences in the diagnosis of dementia and in its effects on the use and costs of health care services. Psychiatr Serv 54: 92-96.

23. Gurland BJ, Wilder DE, Lantigua R, Stern Y, Chen J, et al. (1999) Rates of dementia in three ethnoracial groups. Int J Geriatr Psychiatry 14: 481-493.

24. Demirovic J, Prineas R, Loewenstein D, Bean J, Duara R, et al. (2003) Prevalence of dementia in three ethnic groups: the South Florida program on aging and health. Ann Epidemiol 13: 472-478.

25. Tang MX, Cross P, Andrews H, Jacobs DM, Small S, et al. (2001) Incidence of $A D$ in African-Americans, Caribbean Hispanics, and Caucasians in northern Manhattan. Neurology 56: 49-56.

26. Fillenbaum GG, Heyman A, Huber MS, Woodbury MA, Leiss J, et al. (1998) The prevalence and 3-year incidence of dementia in older Black and White community residents. J Clin Epidemiol 51: 587-595.

27. Hendrie HC, Ogunniyi A, Hall KS, Baiyewu O, Unverzagt FW, et al. (2001) Incidence of dementia and Alzheimer disease in 2 communities: Yoruba residing in Ibadan, Nigeria, and African Americans residing in Indianapolis, Indiana. JAMA 285: 739-747.

28. Odum SM, Springer BD, Dennos AC, Fehring TK (2013) National obesity trends in total knee arthroplasty. J Arthroplasty 28: 148-151.

29. Charlson ME, Pompei P, Ales KL, MacKenzie CR (1987) A new method of classifying prognostic comorbidity in longitudinal studies: development and validation. J Chronic Dis 40: 373-383.

30. Heyman A, Fillenbaum G, Prosnitz B, Raiford K, Burchett B, et al. (1991) Estimated prevalence of dementia among elderly black and white community residents. Arch Neurol 48: 594-598.

31. Froehlich TE, Bogardus ST, Inouye SK (2001) Dementia and race: are there differences between African Americans and Caucasians? J Am Geriatr Soc 49: 477-484.

32. Espino DV, Lewis R (1998) Dementia in older minority populations. Issues of prevalence, diagnosis, and treatment. Am J Geriatr Psychiatry 6: S19-25.
33. Mehta KM, Yaffe K, Pérez-Stable EJ, Stewart A, Barnes D, et al. (2008) Race/ ethnic differences in AD survival in US Alzheimer's Disease Centers. Neurology 70: 1163-1170.

34. Zuckerman IH, Ryder PT, Simoni-Wastila L, Shaffer T, Sato M, Zhao L, et al. (2008) Racial and ethnic disparities in the treatment of dementia among Medicare beneficiaries. J Gerontol B Psychol Sci Soc Sci 63: S328-333.

35. Poon I, Lal LS, Ford ME, Braun UK (2009) Racial/ethnic disparities in medication use among veterans with hypertension and dementia: a national cohort study. Ann Pharmacother 43: 185-193.

36. Holstein J, Chatellier G, Piette F, Moulias R (1994) Prevalence of associated diseases in different types of dementia among elderly institutionalized patients: analysis of 3447 records. J Am Geriatr Soc 42: 972-977.

37. Landi F, Gambassi G, Lapane KL, Sgadari A, Mor V, et al. (1999) Impact of the type and severity of dementia on hospitalization and survival of the elderly. The SAGE Study Group. Dement Geriatr Cogn Disord 10: 121-129.

38. Eaker ED, Mickel SF, Chyou PH, Mueller-Rizner NJ, Slusser JP (2002) Alzheimer's disease or other dementia and medical care utilization. Ann Epidemiol 12: 39-45.

39. Wolf-Klein GP, Siverstone FA, Brod MS, Levy A, Foley CJ, et al. (1988) Are Alzheimer patients healthier? J Am Geriatr Soc 36: 219-224.

40. McCormick WC, Kukull WA, van Belle G, Bowen JD, Teri L, et al. (1994) Symptom patterns and comorbidity in the early stages of Alzheimer's disease. J Am Geriatr Soc 42: 517-521.

41. Sanderson M, Wang J, Davis DR, Lane MJ, Cornman CB, et al. (2002) Comorbidity associated with dementia. Am J Alzheimers Dis Other Demen 17: 73-78.

42. Löppönen MK, Isoaho RE, Räihä IJ, Vahlberg TJ, Loikas SM, et al. (2004) Undiagnosed diseases in patients with dementia--a potential target group for intervention. Dement Geriatr Cogn Disord 18: 321-329.

43. De Carolis A, Giubilei F, Caselli G, Casolla B, Cavallari M, et al. (2011) Chronic obstructive pulmonary disease is associated with altered neuropsychological performance in young adults. Dement Geriatr Cogn Dis Extra 1: 402-408.

44. Sampson EL, Blanchard MR, Jones L, Tookman A, King M (2009) Dementia in the acute hospital: prospective cohort study of prevalence and mortality. $\mathrm{Br} \mathrm{J}$ Psychiatry 195: 61-66

45. Fried TR, Gillick MR (1994) Medical decision-making in the last six months of life: choices about limitation of care. J Am Geriatr Soc 42: 303-307. 